\title{
Focus Issue on Unique Materials, Techniques, and Environments
}

\section{Yves Wouters ${ }^{1}$ - Bruce A. Pint ${ }^{2}$. Daniel Monceau ${ }^{3} \cdot$ Michel Vilasi $^{4}$. Sébastien Chevalier ${ }^{5} \cdot$ Laurence Latu-Romain $^{6} \cdot$ Clara Desgranges $^{7}$}

Received: 12 August 2021 / Revised: 12 August 2021 / Accepted: 12 August 2021 /

Published online: 18 August 2021

(C) The Author(s), under exclusive licence to Springer Science+Business Media, LLC, part of Springer Nature 2021

This focus issue explores a wide range of new materials and characterization techniques as well as unique environments. In situ monitoring techniques are being used to study oxidation behavior of stainless steels and techniques compared to study chromia growth mechanisms. Mo-Si-B compositions are being explored for high-temperature applications as alloys and coatings. Similarly, high entropy alloys also are of interest and are being studied in both isothermal and cyclic conditions.

Yves Wouters

yves.wouters@univ-grenoble-alpes.fr

$\triangle$ Bruce A. Pint

pintba@ornl.gov

Daniel Monceau

daniel.monceau@toulouse-inp.fr

Michel Vilasi

Michel.Vilasi@univ-lorraine.fr

Sébastien Chevalier

sebastien.chevalier@u-bourgogne.fr

Laurence Latu-Romain

Laurence.latu-romain@univ-grenoble-alpes.fr

Clara Desgranges

clara.desgranges@safrangroup.com

1 SIMaP, Universite' Grenoble Alpes, Grenoble, France

2 Materials Science and Technology Division, Oak Ridge National Laboratory, Oak Ridge, TN, USA

3 CNRS CIRIMAT, Université de Toulouse, Toulouse, France

4 IJL, Université de Lorraine, Metz, France

5 ICB, Université de Bourgogne, Dijon, France

6 SIMaP, Université Grenoble Alpes and Ugitech, Grenoble, France

7 Safran-Tech, Châteaufort, France 
Ceramic coatings to protect steel tubes are being evaluated in the laboratory and in the field. Titanium alloys are of interest for a number of industrial applications and present a unique challenge because of their high oxygen solubility. Oxygen diffusion kinetics are being studied and strategies explored to inhibit ingress. New studies on materials made by additive manufacturing explore the effect of metal dusting and water vapor containing environments. Finally, several papers explore materials and environments for nuclear energy including fuels, fuel cladding, and liquid metals, which are also relevant to fusion energy.

The following papers stem from presentations that were given at the 10th International conference on High Temperature Corrosion and Protection of Materials (HTCPM2021), which was held virtually March 29-April 2, 2021.

Publisher's Note Springer Nature remains neutral with regard to jurisdictional claims in published maps and institutional affiliations. 